\title{
Benign Liver Tumors
}

\author{
Karl J. Oldhafer ${ }^{a, b}$ Victoria Habbel ${ }^{a, b}$ Katja Horling ${ }^{c}$ Georgios Makridis $^{a, b}$ \\ Kim Caroline Wagner ${ }^{a, b}$ \\ a Department für Chirurgie, Klinik für Leber-, Gallenwegs- und Pankreaschirurgie, Asklepios Klinik Barmbek, \\ Hamburg, Germany; ${ }^{b}$ Semmelweis University Budapest, Asklepios Campus Hamburg, Hamburg, Germany; ${ }^{\text {C Institut }}$ \\ für Hämatopathologie, Hamburg, Germany
}

\begin{abstract}
Keywords
Benign liver tumors · Focal nodular hyperplasia . Hemangioma $\cdot$ Hepatocellular adenoma
\end{abstract}

\begin{abstract}
Background: Due to the frequent use of medical imaging including ultrasonography, the incidence of benign liver tumors has increased. There is a large variety of different solid benign liver tumors, of which hemangioma, focal nodular hyperplasia (FNH), and hepatocellular adenoma (HCA) are the most frequent. Advanced imaging techniques allow precise diagnosis in most of the patients, which reduces the need for biopsies only to limited cases. Patients with benign liver tumors are mostly asymptomatic and do not need any kind of treatment. Symptoms can be abdominal pain and pressure effects on adjacent structures. The 2 most serious complications are bleeding and malignant transformation. Summary: This review focuses on hepatic hemangioma $(\mathrm{HH}), \mathrm{FNH}$, and $\mathrm{HCA}$, and provides an overview on clinical presentations, surgical and interventional treatment, as well as conservative management. Treatment options for $\mathrm{HHs}$, if indicated, include liver resection, radiofrequency ablation, and transarterial catheter embolization, and should be carefully weighed against possible complications. $\mathrm{FNH}$ is the most frequent benign liver tumor without any risk of malignant transformation, and treatment should only be restricted to symptomatic patients. HCA is associated with the use of oral contraceptives or other steroid medications. Unlike other benign liver tumors, HCA may be complicated by malignant transformation. HCAs have been divided into 6 subtypes based on molecular and pathological features with dif-
\end{abstract}

ferent risk of complication. Key Message: The vast majority of benign liver tumors remain asymptomatic, do not increase in size, and rarely need treatment. Biopsies are usually not needed as accurate diagnosis can be obtained using modern imaging techniques.

(c) 2020 S. Karger AG, Basel

\section{Introduction}

Due to the frequent use of medical imaging including ultrasonography, the incidence of benign liver tumors has increased, most of them being asymptomatic. There is a large variety of solid benign liver tumors of different cellular origin (Table 1). However, the most frequent lesions are hepatic hemangioma $(\mathrm{HH})$, focal nodular hyperplasia (FNH), and hepatocellular adenoma (HCA). As imaging techniques improve, a precise diagnosis is possible in most cases reducing the need for a percutaneous biopsy. However, atypical lesions may require more than one imaging modality. Usually, clinical and radiological findings are sufficient to pinpoint an accurate diagnosis, and additional biopsy is only needed under few circumstances. In the last 10 years, several developments in radiological techniques have been described. A summary of well-established imaging features for benign liver tumors is depicted in Table 2 .

\section{Hemangioma}

The most common benign liver tumor is $\mathrm{HH}$. Its incidence varies from 3 to $20 \%$ [13]. The female/male ratio is 5:1 [14]. Often, $\mathrm{HH}$ is an incidental finding during radio- 
logical imaging [15]. HH are mostly solitary lesions, and sizes range from a few millimeters to up to $30 \mathrm{~cm}$, but most $\mathrm{HH}$ are $<5 \mathrm{~cm}$ in diameter. $\mathrm{HH}>10 \mathrm{~cm}$ is referred to as giant hemangiomas (Fig. 1). In general, $\mathrm{HH}$ are well-

Table 1. Histological classification of benign liver lesions

Epithelial lesions:

- Hepatocytes:

- Hepatocellular adenoma

- Focal nodular hyperplasia

- Nodular regenerative hyperplasia

- Focal fatty change

- Biliary cells:

- Bile duct adenoma

- Biliary hamartoma (von Meyenburg complex)

Nonepithelial lesions:

- Mesenchymal:

- Hemangioma

- Angiomyolipoma

- Lipoma

- Myolipoma

- Heterotopia:

- Adrenal, pancreatic, or spleen tissue

- Others:

- Peliosis hepatis

- Inflammatory pseudotumor demarcated tumors with a spongy red-brown cut surface. Long-term lesions frequently contain white fibrotic areas (Fig. 2). Based on microscopic findings, $\mathrm{HH}$ can be divided into 3 main subtypes: cavernous, capillary, and anastomosing $\mathrm{HH}$. The cavernous $\mathrm{HH}$ is the most common type. It is characterized by widely dilated vascular channels with fibrous walls lined by a single layer of flat endothelial cells. Cytological atypia or mitosis are absent. Usually, the blood-filled channels can show fresh or organized thrombi (Fig. 2). Large und long-existing lesions with partial or complete sclerosis are known as sclerosed hemangiomas. It is known that $\mathrm{HH}$ arises from vascular malformation; however, its exact pathogenesis remains to be elucidated. Recently, it has been shown that an increase in vascular endothelial growth factor (VEGF) plays an essential role in the development of hemangioma [16]. This concept was supported by case reports showing hemangioma shrinkage following anti-VEGF treatment [17]. However, Lee et al. [18] found no effect in 21 antiVEGF-treated patients. Although very few hemangiomas have estrogen receptors, growth of hemangiomas has been observed after hormone replacement therapy, oral contraceptives, and pregnancy [19]. The direct mechanisms of those hormone effects are still unknown. Current evidence does not support a contraindication for oral

Table 2. Imaging features of benign liver lesions [1-12]

\begin{tabular}{|c|c|c|c|}
\hline $\begin{array}{l}\text { Entity/imaging } \\
\text { modality }\end{array}$ & Hemangioma & Focal nodular hyperplasia & Hepatocellular adenoma (HCA) \\
\hline $\begin{array}{l}\text { Ultrasound } \pm \\
\text { contrast } \\
\text { enhancement }\end{array}$ & $\begin{array}{l}\text { Homogenous, hyperechoic, sharp rim } \\
\text { Atypical: peripheral and globular } \\
\text { enhancement followed by central } \\
\text { enhancement in delayed phases } \\
\text { Absence of halo sign } \\
\text { Sclerosing hemangiomas: very slow } \\
\text { filling and calcified or hyalinized } \\
\text { hemangiomas }\end{array}$ & $\begin{array}{l}\text { Slightly hypo-/isoechoic } \\
\text { Very rarely: hyperechoic } \\
\text { Strong and homogeneous } \\
\text { enhancement (arterial phase) } \\
\text { Color Doppler: central arteries } \\
\text { have a spoke wheel pattern }[4,5]\end{array}$ & $\begin{array}{l}\text { Arterial phase: homogeneous contrast } \\
\text { enhancement, rapid complete centripetal filling } \\
\text { Early portal venous phase: isoechoic }\end{array}$ \\
\hline $\begin{array}{l}\text { Computed } \\
\text { tomography }\end{array}$ & $\begin{array}{l}\text { Inhomogeneous peripheral } \\
\text { nodular enhancement } \\
\text { isoattenuating to the aorta, } \\
\text { progressive centripetal } \\
\text { contrast filling }\end{array}$ & $\begin{array}{l}\text { Central vascular supply } \\
\text { Arterial phase: homogenous } \\
\text { hyperdense } \\
\text { Portal phase: similar to adjacent } \\
\text { liver [6-8] }\end{array}$ & $\begin{array}{l}\text { Clear margins with peripheral enhancement } \\
\text { Homogenous > heterogenous } \\
\text { Steatotic: hypodense, } \\
\text { Hemorrhagic: hyperdense }\end{array}$ \\
\hline
\end{tabular}



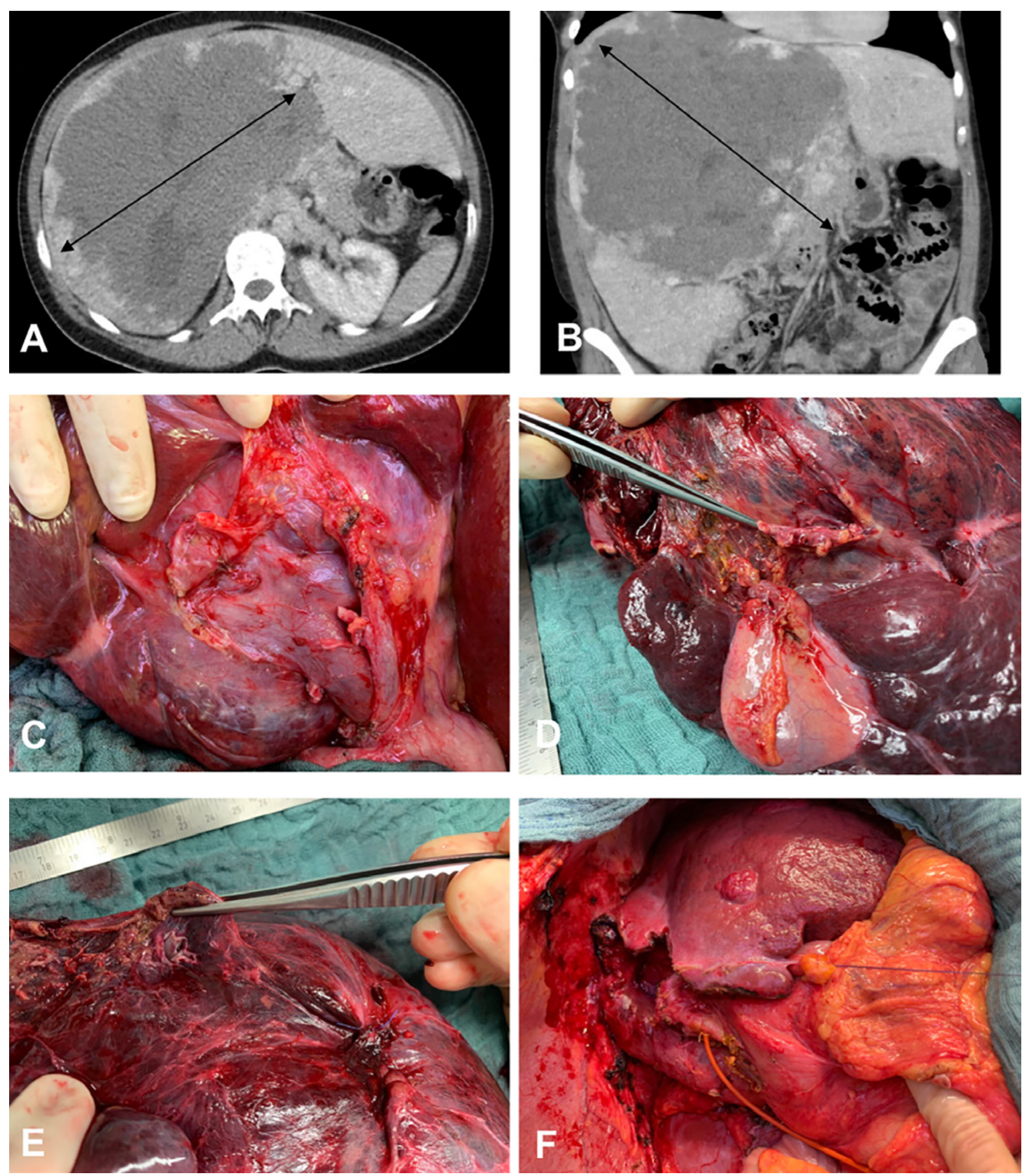

Fig. 1. A 36-year-old female patient with a giant hepatic hemangioma occupying segments IV-VIII. A CT, axial section showing a lesion $22-23 \mathrm{~cm}$ in diameter (bidirectional arrows). B CT, coronal section. C Intraoperative view of the hemangioma pushing the right portal vein anteriorly. D Enucleation seemed not to be possible (the right hepatic vein was close and in some parts within the hemangioma); therefore, an extended right hepatectomy was per-

formed after portal vein embolization. The picture shows the surgical specimen with normal hepatic parenchyma and hemangioma. E Surgical specimen with a view to the right hepatic vein. F Situs after extended right hepatic resection (segments IV-VIII). The hypertrophied segments II and III are shown. There is a small hepatic hemangioma in segment III. 


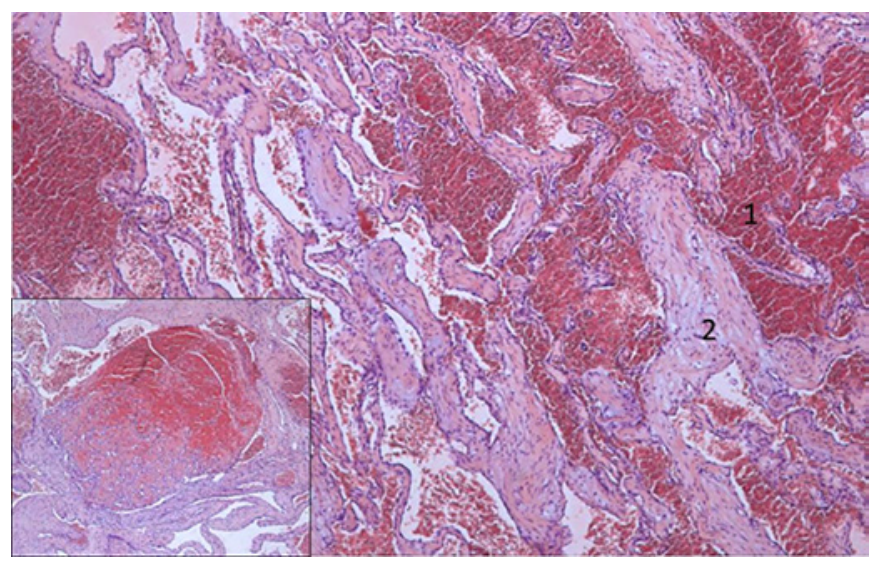

Fig. 2. HE-stained sections show the classic morphology of a cavernous hemangioma with widely dilated vascular channels (1) lined by flattened inconspicuous endothelial cells and fibrous walls (2) and focal organized thrombi (inset).

contraceptives or hormone substitution in hemangioma patients [2].

Even though most hemangiomas are asymptomatic, large lesions may cause pressure on adjacent structures, including compression of the vena cava, portal vein, and the bile duct, leading to abdominal pain, discomfort, fullness in the right upper quadrant, nausea, and early satiety [20]. Rare symptoms are fever, jaundice, dyspnea, highoutput cardiac failure, and hemobilia [21,22]. Spontaneous bleeding of $\mathrm{HH}$ is uncommon [23]. Donati et al. [23] found only 46 cases with spontaneous bleeding in a literature review between 1898 and 2010. Low-grade fever, weight loss, abdominal pain, anemia, thrombocytosis, and increased fibrinogen level can be caused by inflammation due to partial thrombosis of the hemangioma. The Kasabach-Merritt syndrome represents a rare complication of giant $\mathrm{HH}$ [24]. This coagulopathy, which consists of intravascular coagulation, clotting, and fibrinolysis within the hemangioma, may progress to secondary increased systemic fibrinolysis and thrombocytopenia. The Kasabach-Merritt syndrome has an incidence ranging from $0.3 \%$ in all hemangiomas up to $26 \%$ in hemangiomas $>15 \mathrm{~cm}[20,25]$. It is life-threatening but reversible after removal of the hemangioma.

Usually, liver tests including alkaline phosphatase and $\gamma$-GT are normal in patients with hemangioma. If patients present with an active cholestasis, it is due to the pressure on the bile duct system caused by the hemangioma.

\section{Management}

Small, asymptomatic hemangiomas do not need treatment or follow-up. In $\mathrm{HHs}>5 \mathrm{~cm}$, follow-up at 6-12 months has been suggested to assess the growth rate [26].
There is no need to make a change in specific lifestyle measures for patients with asymptomatic hemangiomas, and there is no evidence that the use of oral contraceptives or pregnancy has a negative impact on patients with HHs. Regardless of the size, treatment should be restricted only to symptomatic patients with pressure to adjacent organs or complications such as the Kasabach-Merritt syndrome and rupture with intraabdominal bleeding. Inability to exclude malignancy is also an indication for resection.

However, abdominal pain in hemangioma patients should be carefully analyzed. Other possible causes should be ruled out before definitive treatment is decided upon.

\section{Surgery}

Surgery remains the most common treatment for symptomatic HHs (Fig. 1). In general, the surgical armamentarium consists of liver resection - including hypertrophy concepts like preoperative portal vein embolization, enucleation, hepatic artery ligation, and liver transplantation [27-32]. The choice of the procedure depends on HH size, number, and location, the surgeon's experience, and the institutional resources. Several studies comparing enucleation with resection showed that enucleation is associated with lower morbidity, shorter operation time, less blood loss, and fewer complications [28, 29]. Furthermore, enucleation can preserve more hepatic parenchyma [28]. However, a single-center study in 86 patients with hemangiomas $>10 \mathrm{~cm}$ showed no difference between enucleation and resection regarding operation time, blood loss, complications, and hospital stay [33].

The enucleation of centrally located hemangiomas requires a significantly longer vascular inflow occlusion and operating time, and more blood transfusions than enucleation of peripherally located hemangiomas [31].

Recently, laparoscopic liver resection has gained widespread acceptance and is considered to be a safe approach for the management of benign liver lesions. A propensity score matching analysis between laparoscopic and open $\mathrm{HH}$ surgery showed that the laparoscopic approach was associated with less blood loss, shorter postoperative hospital stay, and lower complication rates than the open approach [34]. However, short-term "quality of life" outcomes did not differ between the different treatment groups [34].

On rare occasions, even liver transplantations as an extreme surgical approach have been performed in patients suffering from HHs [35]. Published studies are mainly limited to small case series. However, Sundar Alagusundaramoorthy et al. [30] analyzed the results of liver transplantations for benign solid tumors of the United Network of Organ Sharing. Of 87,280 transplantations, 25 have been performed for $\mathrm{HH}$, and their overall survival rates were $87.8,81.5$, and $74.8 \%$ at $1-, 3$-, and 5-year follow-ups, respectively. Due to the significant postop- 

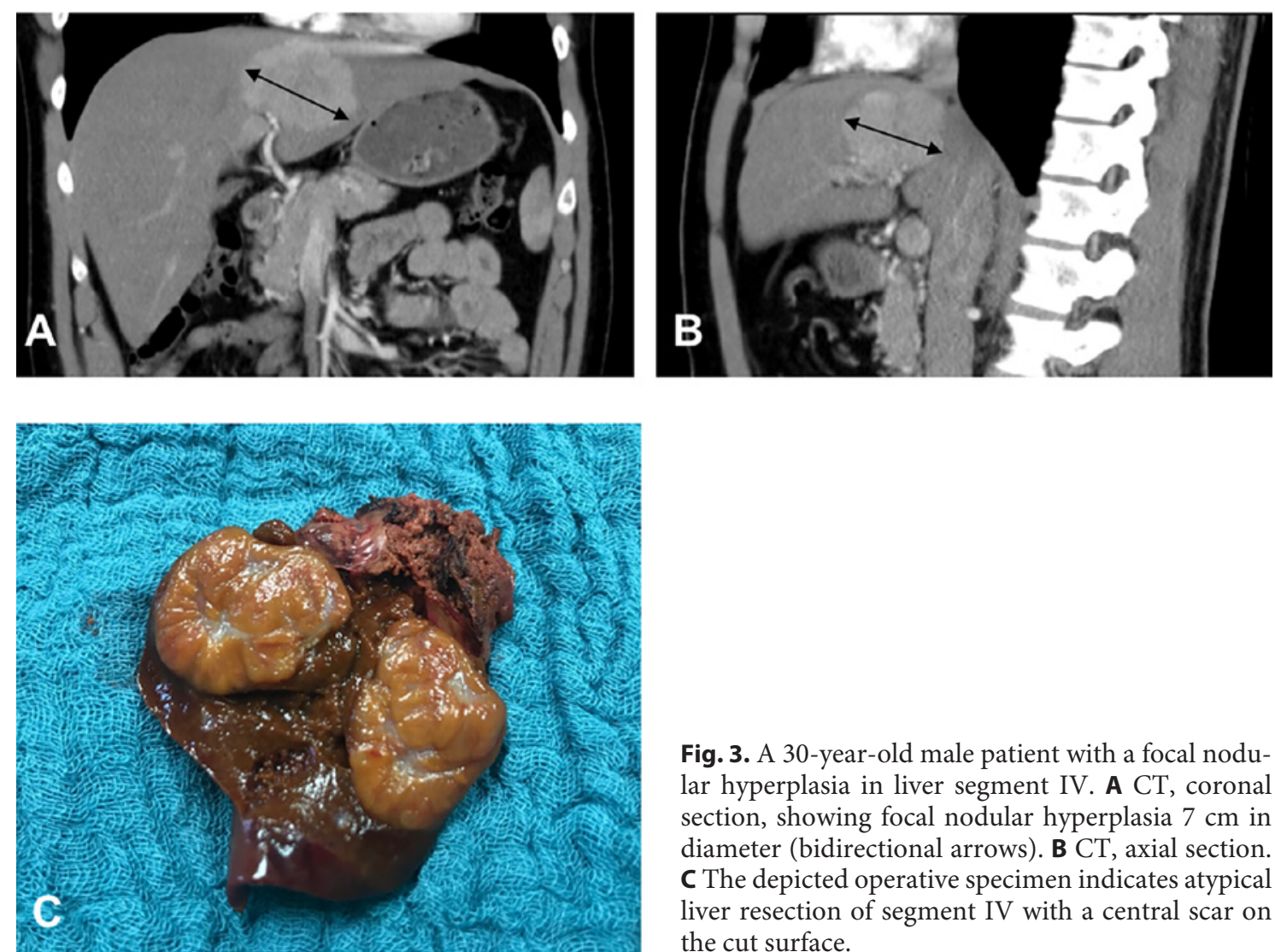

Fig. 3. A 30-year-old male patient with a focal nodular hyperplasia in liver segment IV. A CT, coronal section, showing focal nodular hyperplasia $7 \mathrm{~cm}$ in diameter (bidirectional arrows). B CT, axial section. C The depicted operative specimen indicates atypical liver resection of segment IV with a central scar on the cut surface.

erative morbidity and shortage of donor livers, the indication for such an aggressive therapy has yet to be defined. So far, liver transplantation should be reserved for unresectable giant HHs causing severe symptoms, failure of previous interventions, or life-threatening complications such as the Kasabach-Merritt syndrome [32].

\section{Nonsurgical Management}

Since surgical treatment can be associated with massive intraoperative blood loss, long operating and hospitalization times and perioperative complications, such as bile leakage for example, nonsurgical treatment options should be considered. However, no consensus exists among surgeons and interventional radiologists. Transcatheter arterial embolization (TAE) has been performed to control acute hemorrhage or to shrink $\mathrm{HHs}$ prior to surgery, which was confirmed in case reports [36, 37]. Substances used for TAE are, for example, metallic coils, polyvinyl alcohol, Gelfoam particles, and liquid agents such as N-butyl-2-cyanoacrylate and bleomycin-lipiodol [36-38]. A recent study including 23 patients and $29 \mathrm{HHs}$ treated with TAE using bleomycin-lipiodol showed a 50\% reduction in the hemangioma volume in 17 of 23 patients [39].

Available studies are limited due to retrospective design and small interventional sample sizes, thus prospective studies and longer clinical follow-ups are necessary to determine the exact role of TAE in the treatment armamentarium of HHs.

Radiofrequency ablation (RFA) has been reported as an alternative treatment of hemangiomas [40-42]. RFA can be used percutaneously, laparoscopically, or during open surgery. RFA is usually performed under ultrasound (US) guidance, but CT guidance for percutaneous RFA is also suitable for hemangiomas located deeply in liver parenchyma [40]. Laparoscopic RFA with US guidance is preferred for subcapsular HHs [41]. Compared with open resection, laparoscopic RFA is associated with shorter operative time, less pain, and shorter hospital stay [42].

\section{Focal Nodular Hyperplasia}

FNH is the second most common benign liver tumor (Fig. 3). Its incidence is between 0.3 and 3\% [13], and it is mostly found at 30-40 years of age [43]. The role of hormones in FNH development is supported by its high female predominance (female:male ratio of 9:1) and high prevalence amongst women taking oral contraceptives [44]. Recently, estrogen receptor expression was found in 12 of $13 \mathrm{FNH}$ tissue samples [45]. The grossly well-demarcated lesion does not show a capsule, and on cut section, lobulated, firm parenchyma with slightly lighter col- 


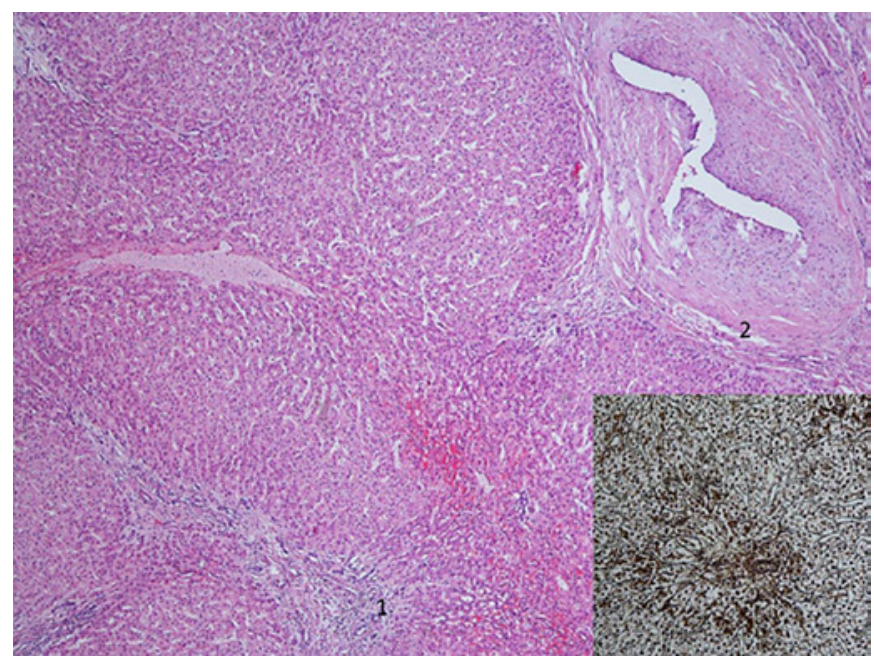

Fig. 4. Focal nodular hyperplasia shows characteristic nodular cirrhosis-like architecture with ductular reaction in fibrous septa (1) and thick-walled abnormal arteries (2). Reticulin with Gomori silver staining demonstrated a retained normal reticulin framework (inset).

or than the surrounding liver presents. Eye catching and very characteristic is the presence of one or more stellate scars (Fig. 3). The liver parenchyma, by definition, is noncirrhotic. Histologically, FNH looks like a focal cirrhosis because of fibrous bands encompassing groups of benign hepatocytes, which could be a potential pitfall in needle biopsy (Fig. 4). True portal tracts are absent. Bile ducts are replaced by ductular proliferation along the fibrous septa, and, characteristically, there are arteries with medial hypertrophy und intimal fibrosis, so-called dysplastic arteries. FNH occurs solitary in $80-95 \%$ and is usually $<5 \mathrm{~cm}$ in diameter. In up to $20 \%$, multiple FNH occur, sometimes in association with hemangioma or HCA [46]. $\mathrm{FNH}$ is considered as a hyperplastic, regenerative response to arterial hyperperfusion and shunting with characteristic anomalous arteries found in the center of the nodules [47]. FNH might also be associated with vascular disorders of the liver, as Gincul et al. [48] found FNH nodules in $13.7 \%$ of patients with hereditary hemorrhagic telangiectasia, and Cazals-Hatem et al. [49] identified them in 9 of 17 explanted livers with Budd-Chiari syndrome. Moreover, congenital absence of portal flow or portal vein thrombosis with subsequent hepatic arterialization is associated with the development of FNH [50, 51].

There is no evidence for malignant transformation of FNH [52]. The majority of patients with FNH is asymptomatic. Only a few patients with large FNH show symptoms, such as abdominal pain or discomfort, due to pressure effects on adjacent organs [53]. Rupture, necrosis, or bleeding is exceptional [54]. As there is most often no change in blood parameters, laboratory tests are not helpful for making the diagnosis of FNH. The natural course of FNH is uneventful, with very few complications and changes over time. However, enlargement of FNHs during oral contraceptive medication and pregnancy have been reported [55]. Therefore, asymptomatic patients should be managed conservatively if the diagnosis is firmly established [56]. Follow-up controls at 6 months are sufficient to prove the stability of the lesion and its benign nature, and no long-term follow-up is routinely required afterwards. Surgery should strictly be considered for patients with symptomatic or highly suspicious lesions, where malignancy cannot be ruled out with modern imaging or even biopsy. In some symptomatic patients with large $\mathrm{FNH}$, where a risky resection would be needed, TAE has been successful $[10,57]$. Experience with TAE shows that it could be an attractive treatment option to decrease the size of the lesions and, therefore, symptom relief [58, 59]. Furthermore, RFA has been described as an effective treatment for symptomatic FNH [60].

As numerous reports regarding FNH during pregnancy have been published, the association with endogenous and/or exogenous estrogens is very likely. Small lesions seem not to be a significant risk for a successful pregnancy, although observation is strongly recommended [56].

\section{Hepatocellular Adenoma}

HCA is a benign hepatic tumor which occurs predominantly in young and middle-aged women who take oral contraceptives or other steroid medications (Fig. 5) [61]. The annual incidence is 3-4 per 100,000 in women who have used oral contraceptives over a sustained period [62].

Baum et al. [63] first described the association between oral contraceptives and HCA occurrence in 1973. In the 1960s, benign liver tumors were in general relatively rare until the introduction of oral contraceptives [64]. Between 1918 and 1954, only 2 HCA cases were found in 48,900 autopsies performed in the Los Angeles General Hospital [65]. Estrogens seem to be a predominant factor for the development of HCA. The positive correlation between oral contraceptives and HCA incidence is dose dependent, as spontaneous regression of HCAs after estrogen withdrawal has been observed [66]. Androgen intake is also associated with the development of HCA [67]. Furthermore, the influence of obesity on the development of $\mathrm{HCA}$ is suggested [68], as recently a higher incidence of HCAs in patients suffering from nonalcoholic steatohepatitis has been reported [1].

HCA development is associated with several genetic syndromes, including glycogen storage diseases, particularly with type Ia glycogenesis, in which more than half of 

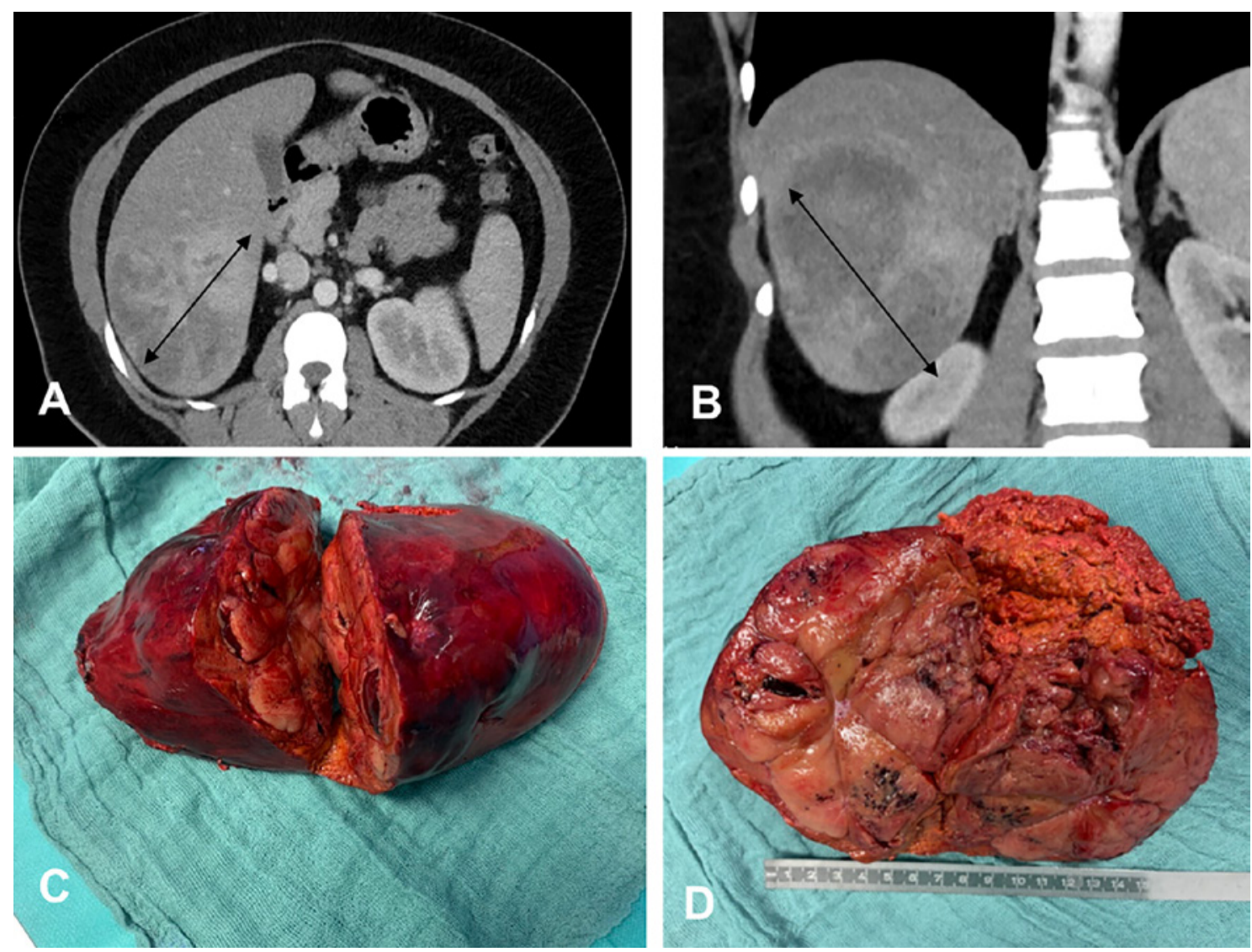

Fig. 5. A 32-year-old female patient with hepatic adenoma. A The tumor is $10 \mathrm{~cm}$ in diameter (bidirectional arrows) in segments VI and VII, coronal section. B CT, axial section. C, D Surgical specimen of an atypical liver resection of segments VI and VII (C) and of normal hepatic parenchyma and hepatic hemangioma visible on the cut surface (D).

patients have multiple tumors [69]. Hepatic vascular abnormalities, including portal deprivation or both intraand extrahepatic portosystemic venous shunts, are involved in the development of HCAs [1].

HCA is a heterogeneous entity that includes several tumor subtypes, which are associated with the risk of various complications (Table 3). First HCA was divided into 4 subtypes according to genomic analysis: inflammatory HCA (I-HCA), hepatocyte nuclear factor (HNF) 1A-mutated HCA (H-HCA), $\beta$-catenin-activated HCA ( $\beta$-HCA), and unclassified HCA [70]. Later, Nault et al. [71] described 6 molecular subtypes of HCA (Table 3). The $\beta$-HCA group was additionally subdivided into 2 subgroups, exon $3 \beta$-catenin-mutated and exons 7-8 $\beta$-catenin-mutated HCA [71]. The different HCA subtypes carry specific types of risks (Table 3 ). For the sonic hedgehog HCA, Nault et al. [71] found a higher risk for symptomatic bleeding. Independent of size, in males, HCAs bear an increased risk of malignant transformation.

Histologically, HCAs arise in noncirrhotic liver and appear as circumscribed nonencapsulated lesions. The yellow to brown color and soft to dense texture depends on the degree of hemorrhage and cystic changes. Microscopic appearance differs depending on the subtype, but the lack of portal tracts and isolated naked arteries is common in all subtypes (Fig. 6). To specify a certain subtype, there are several characteristics in combination with immunohistochemistry and molecular features. Diffuse steatosis is commonly seen in HNF1a-inactivated HCA. A marked, predominantly lymphocytic inflammation resembling portal tracts at low magnification is the main feature of the inflammatory subtype. It is associated with alcohol consumption and/or an increased BMI and has an increased risk of hemorrhage. $\beta$-Catenin-activated HCAs do not show any special morphological features. Nuclear $\beta$-catenin expression and diffuse glutamine synthetase reactivity as a surrogate marker of $\beta$-catenin activation are their hallmarks. $\beta$-Catenin HCA is more likely to show cytological atypia. A small subset of adenomas remains unclassified even after immunostaining. Key differentiating features of HCA and HCC are a preserved reticulin framework and absence of mitosis in HCA. 


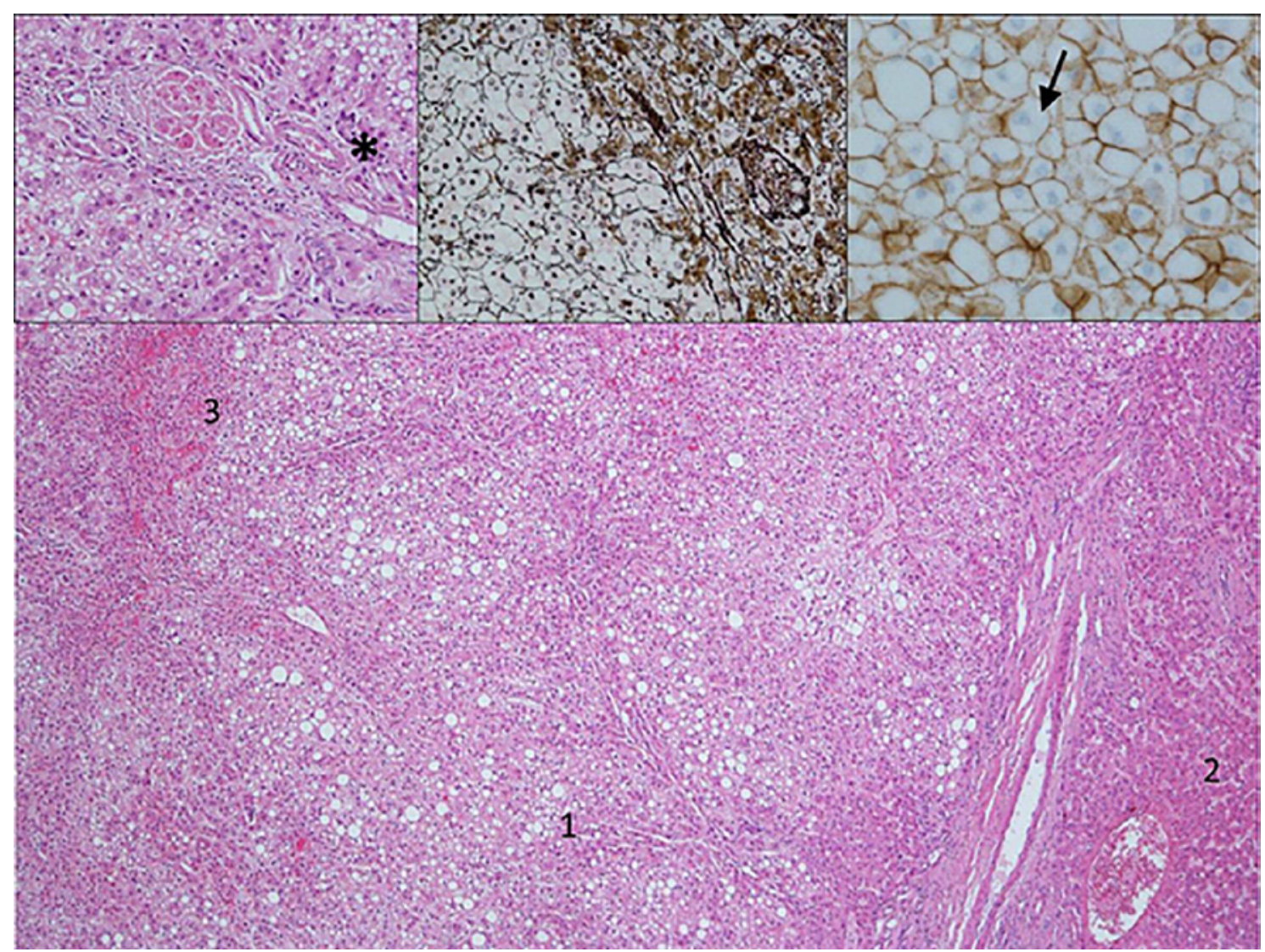

Fig. 6. Hepatocellular adenoma with fatty changes limited to the lesion (1) but absent in normal liver (2). Hemorrhage is a common feature (3). Insets: Higher magnification (left inset) does not show portal tracts but so-called naked arteries $(*)$ and, in comparison to hepatocellular carcinoma, no nuclear atypia or mitotic activity. Reticulin (middle inset) with Gomori silver staining demonstrates a preserved reticulin framework somewhat slightly reduced in the lesion versus the normal liver. In this case, $\beta$-catenin staining (right inset) was negative with only membranous and no nuclear reactivity. Brown, cell membrane; blue, nucleus.

Table 3. Molecular classification of hepatocellular adenoma with information about frequency, risk factors, epidemiology, and symptoms/complications

\begin{tabular}{|c|c|c|c|c|c|}
\hline $\begin{array}{l}\text { Classes } \\
2007[58]\end{array}$ & $\begin{array}{l}\text { Classes } \\
2017[52]\end{array}$ & $\begin{array}{l}\text { Frequency, } \\
\%\end{array}$ & Risk factors & Epidemiology & $\begin{array}{l}\text { Symptoms/ } \\
\text { complications }\end{array}$ \\
\hline $\begin{array}{l}\text { HNF1A } \\
\text { inactivated }\end{array}$ & $\begin{array}{l}\text { HNF1A } \\
\text { inactivated }\end{array}$ & $40-50$ & Oral contraception & $\begin{array}{l}\text { Female, } \\
\text { liver adenomatosis }\end{array}$ & \\
\hline \multirow[t]{2}{*}{$\begin{array}{l}\beta \text {-Catenin } \\
\text { activated }\end{array}$} & $\beta$-Catenin exons $7 / 8$ & 3 & $\begin{array}{l}\text { Oral contraception, } \\
\text { high alcohol consumption, } \\
\text { obesity }\end{array}$ & $\begin{array}{l}\text { Young age, } \\
\text { solitary tumor }\end{array}$ & \\
\hline & $\beta$-Catenin exon 3 & 7 & $\begin{array}{l}\text { Androgen, } \\
\text { liver vascular disease }\end{array}$ & $\begin{array}{l}\text { Male, young age, } \\
\text { solitary tumor }\end{array}$ & $\begin{array}{l}\text { Malignant } \\
\text { transformation }\end{array}$ \\
\hline Inflammatory & $\begin{array}{l}\text { Inflammatory (mixed forms } \\
\text { with } \beta \text {-catenin subtypes) }\end{array}$ & $30-35$ & Oral contraception & $\begin{array}{l}\text { Older age, } \\
\text { inflammatory syndrome }\end{array}$ & $\begin{array}{l}\text { Elevated GGT and } \\
\text { ALP }\end{array}$ \\
\hline Unclassified & $\begin{array}{l}\text { Sonic hedgehog } \\
\text { Unclassified }\end{array}$ & $\begin{array}{l}4 \\
7\end{array}$ & Oral contraception, obesity & - & Bleeding \\
\hline
\end{tabular}

HNF1A, hepatocyte nuclear factor $1 \alpha$. 
The majority of patients with HCA are asymptomatic and diagnosed incidentally during liver ultrasound examinations. In symptomatic patients, the most common symptom is abdominal pain. The main complication of HCA is hemorrhage; it occurs in approximately $25 \%$ of patients [72]. In large tumors ( $>5 \mathrm{~cm}$ in diameter), visualization of arteries within the HCA, location in the left lateral liver, and exophytic growth are risk factors for hemorrhage [72, 73].

The overall risk of malignant transformation in HCA is reported to be $5-6 \%$, but it is probably lower, as it is difficult to distinguish between HCA and well-differentiated hepatocellular carcinoma (HCC) in imaging and even histopathologically. HCA may transform into HCC (adenoma-carcinoma sequence), but the natural history of this progression is not well defined and understood $[74,75]$.

The risk of malignant transformation can vary from virtually 0 to almost $50 \%$, depending on patient-related factors, tumor size, and pathology classification, which makes the relevance of its overall estimation questionable. Risk factors for malignant transformation include sex, androgen use, $\beta$-catenin HCA subtype, and tumor diameter $>5 \mathrm{~cm}$. A substantial number of I-HCAs can also contain $\beta$-catenin mutations and are at risk of malignant progression.

Up to one third of patients diagnosed with HCA have multiple lesions. Multiple HCAs ( $>3$ lesions) of various sizes are termed liver adenomatosis [76]. In patients with adenomatosis, the risk of complications is not higher than in patients with a solitary HCA; therefore, adenomatosis patients do not have to be treated differently.

\section{Management}

Imaging for differential diagnosis between HCC and HCA can be challenging. In rare cases, HCCs have been misinterpreted as HCAs. Modern CT and MRI enhanced by gadobenate dimeglumine or gadoxetate disodium are very effective in differentiating HCA from $\mathrm{FNH}$ or other lesions, and also in identifying the HCA subtypes, if interpreted by a radiologist experienced in hepatobiliary lesions (Table 2) [11, 77]. If not, a biopsy of the lesion can be indicated to define the subtype according to their specific genetic and molecular markers. However, biopsy can be risky due to the vascular nature of $\mathrm{HH}$ and should, therefore, be reserved for cases in which the histology will have an impact on treatment decision [15].

In male patients, HCAs should be resected regardless of the size due to the high risk of developing malignancy. In female patients with HCAs $<5 \mathrm{~cm}$, cessation of hormonal therapy with MRI surveillance is recommended as initial management. In small HCAs that cannot be characterized by MRI, percutaneous biopsy has been advocated by some groups. For female patients with persistent
HCAs $>5 \mathrm{~cm}$ after cessation of hormonal therapy, surgical management is indicated. The risk of vascular invasion or lymph node involvement is reduced in HCA patients; therefore, a wide resection margin or regional lymphadenectomy does not seem necessary. Thus, if resection of HCA is indicated, a laparoscopic approach should be preferred, because it seems to be superior to open surgery in terms of quality of life after surgery and operative outcomes [78].

In patients with multiple HCAs, only tumors $>5 \mathrm{~cm}$ in diameter should be resected. For smaller lesions in female patients, pathological confirmation is not mandatory, and regular follow-up is recommended. Indeed, followup data of HCAs $<5 \mathrm{~cm}$ show that most remain stable in size, and sometimes even decrease or disappear at all.

To manage bleeding HCAs, TAE is widely used in order to prevent recurrence and occasionally even to reduce tumor size. However, preoperative TAE can be an option to reduce intraoperative blood loss [79]. Although patients with a ruptured HCA may display severe abdominal pain and have free intraperitoneal hemorrhage, hemodynamic stability is common in the majority of these patients making a conservative approach possible. After bleeding, in the absence of tumor or in the presence of minimal residual tumor tissue on MRI, a conservative nonoperative approach with MRI surveillance might be considered. However, when HCA tissue is left in a largesized HCA, surgical resection should be performed. The efficacy of TAE on tumor regression in hemorrhage lesions has led some groups to consider using TAE electively in nonbleeding HCAs [80]. Liver transplantation might only be considered in very few situations, including multiple unresectable lesions in men, a large HCA associated with intrahepatic venous shunt, and in patients with glycogen storage disorders unresponsive to medical treatment [81].

\section{Conclusion}

Benign liver tumors are often diagnosed randomly. HHs are the most frequent lesions. The majority of benign liver tumors does not need any kind of treatment, and even follow-up is only necessary in some patients. In asymptomatic $\mathrm{HH}$ and $\mathrm{FNH}$ regardless of their size, no intervention is required. Patients with symptomatic $\mathrm{HH}$ and $\mathrm{FNH}$ and an impaired quality of life can be referred for surgery or nonsurgical therapeutic modalities, such as radiofrequency or TAE. The situation for patients with HCA is different, as severe bleeding and malignant transformation are associated risk factors. HCA can be stimulated by metabolic or hormonal abnormalities. Therefore, oral contraceptives and anabolic steroids should be avoided after being diagnosed with HCA. Six subtypes of HCA 
are identified on the basis of genomic analysis. They display different risk profiles. Therefore, a precise diagnosis including the identification of the subtype is helpful for treatment decisions. This can be obtained by modern MRI technology in most cases. Biopsies are seldom necessary. In male patients, HCA should be resected regardless of the size. In women with HCA $<5 \mathrm{~cm}$, cessation of hormonal therapy is recommended with MRI surveillance. In women with $\mathrm{HCA}>5 \mathrm{~cm}$ after cessation of hormonal therapy, surgical management is recommended. Pregnancy is not generally contraindicated for patients with $\mathrm{HCA}<5 \mathrm{~cm}$. Since the majority of patients with operated benign liver tumors are suffering from tumors of larger size and of difficult locations, diagnosis and surgery should be performed in experienced hepatobiliary centers.

\section{Statements of Ethics}

Since this is a review article, institutional approval and patient consent were not required.

\section{Conflict of Interest Statement}

All authors have no conflicts of interest to declare.

\section{Funding Sources}

Authors received no funding for this paper.

\section{Author Contributions}

K.J.O. and K.C.W. wrote the manuscript, K.H. added the pathology part, and V.H. and G.M. critically revised the manuscript.

\section{References}

1 European Association for the Study of the Liver (EASL). EASL Clinical Practice Guidelines on the management of benign liver tumours. J Hepatol. 2016 Aug;65(2):386-98.

2 Marrero JA, Ahn J, Rajender Reddy K; American College of Gastroenterology. ACG clinical guideline: the diagnosis and management of focal liver lesions. Am J Gastroenterol. 2014 Sep;109(9):1328-47.

3 Stark DD, Felder RC, Wittenberg J, Saini S, Butch RJ, White ME, et al. Magnetic resonance imaging of cavernous hemangioma of the liver: tissue-specific characterization. AJR Am J Roentgenol. 1985 Aug;145(2):213-22.

4 Vilgrain V, Fléjou JF, Arrivé L, Belghiti J, Najmark D, Menu Y, et al. Focal nodular hyperplasia of the liver: MR imaging and pathologic correlation in 37 patients. Radiology. 1992 Sep;184(3):699-703.

5 Buetow PC, Pantongrag-Brown L, Buck JL, Ros PR, Goodman ZD. Focal nodular hyperplasia of the liver: radiologic-pathologic correlation. Radiographics. 1996 Mar;16(2):369-88.

6 Brancatelli G, Federle MP, Grazioli L, Blachar A, Peterson MS, Thaete L. Focal nodular hyperplasia: CT findings with emphasis on multiphasic helical CT in 78 patients. Radiology. 2001 Apr;219(1):61-8.

7 Kim MJ, Lim HK, Kim SH, Choi D, Lee WJ, Lee SJ, et al. Evaluation of hepatic focal nodular hyperplasia with contrast-enhanced gray scale harmonic sonography: initial experience. J Ultrasound Med. 2004 Feb;23(2):297305.

8 Dietrich CF, Schuessler G, Trojan J, Fellbaum C, Ignee A. Differentiation of focal nodular hyperplasia and hepatocellular adenoma by contrast-enhanced ultrasound. Br J Radiol. 2005 Aug;78(932):704-7.

9 Mortelé KJ, Praet M, Van Vlierberghe H, Kunnen M, Ros PR. CT and MR imaging findings in focal nodular hyperplasia of the liver: radiologic-pathologic correlation. AJR Am J Roentgenol. 2000 Sep;175(3):687-92.
10 Kehagias D, Moulopoulos L, Antoniou A, Hatziioannou A, Smyrniotis V, Trakadas S, et al. Focal nodular hyperplasia: imaging findings. Eur Radiol. 2001;11(2):202-12.

11 Laumonier H, Bioulac-Sage P, Laurent C, Zucman-Rossi J, Balabaud C, Trillaud H. Hepatocellular adenomas: magnetic resonance imaging features as a function of molecular pathological classification. Hepatology. 2008 Sep;48(3):808-18.

12 Ronot M, Bahrami S, Calderaro J, Valla DC, Bedossa P, Belghiti J, et al. Hepatocellular adenomas: accuracy of magnetic resonance imaging and liver biopsy in subtype classification. Hepatology. 2011 Apr;53(4):1182-91. Erratum in: Hepatology. 2011 Sep;54(3):1114.

13 Karhunen PJ. Benign hepatic tumours and tumour like conditions in men. J Clin Pathol. 1986 Feb;39(2):183-8.

14 Mergo PJ, Ros PR. Benign lesions of the liver. Radiol Clin North Am. 1998 Mar;36(2):31931.

15 Shaked O, Siegelman ES, Olthoff K, Reddy KJ. Biologic and clinical features of benign solid and cystic lesions of the liver. Clin Gastroenterol Hepatol. 2011;9(7):P4547-62.e4.

16 Ou JM, Yu ZY, Qiu MK, Dai YX, Dong Q, Shen J, et al. Knockdown of VEGFR2 inhibits proliferation and induces apoptosis in hemangioma-derived endothelial cells. Eur J Histochem. 2014 Mar;58(1):2263.

17 Yamashita S, Okita K, Harada K, Hirano A, Kimura T, Kato A, et al. Giant cavernous hepatic hemangioma shrunk by use of sorafenib. Clin J Gastroenterol. 2013 Feb;6(1):55-62.

18 Lee M, Choi JY, Lim JS, Park MS, Kim MJ, Kim H. Lack of anti-tumor activity by antiVEGF treatments in hepatic hemangiomas. Angiogenesis. 2016 Apr; 19(2):147-53.

19 Glinkova V, Shevah O, Boaz M, Levine A, Shirin $H$. Hepatic haemangiomas: possible association with female sex hormones. Gut. 2004 Sep;53(9):1352-5.
20 Sakamoto Y, Kokudo N, Watadani T, Shibahara J, Yamamoto M, Yamaue H; Japanese Society of Hepato-Biliary-Pancreatic Surgery. Proposal of size-based surgical indication criteria for liver hemangioma based on a nationwide survey in Japan. J Hepatobiliary Pancreat Sci. 2017 Jul;24(7):417-25.

21 Liu X, Yang Z, Tan H, Zhou W, Su Y. Fever of Unknown Origin Caused by Giant Hepatic Hemangioma. J Gastrointest Surg. 2018 Feb; 22(2):366-7.

22 Smith AA, Nelson M. High-Output Heart Failure from a Hepatic Hemangioma With Exertion-Induced Hypoxia. Am J Cardiol. 2016 Jan;117(1):157-8.

23 Donati M, Stavrou GA, Donati A, Oldhafer KJ. The risk of spontaneous rupture of liver hemangiomas: a critical review of the literature. J Hepatobiliary Pancreat Sci. 2011 Nov; 18(6):797-805

24 Kasabach HH, Merritt KK. Capillary hemangioma with extensive purpura: report of a case. Am J Dis Child. 1940;59(5):1063-70.

25 Miura JT, Amini A, Schmocker R, Nichols S, Sukato D, Winslow ER, et al. Surgical management of hepatic hemangiomas: a multiinstitutional experience. HPB (Oxford). 2014 Oct;16(10):924-8.

26 Bajenaru N, Balaban V, Săvulescu F, Campeanu I, Patrascu T. Hepatic hemangioma -review- [Review]. J Med Life. 2015;8(Spec Issue):4-11.

27 Strohmaier A, Wagner KC, Reese T, FardAghaie M, Makridis G, Rittberg Y, et al. Extended liver resection including hypertrophy concept with portal venous embolisation for giant hemangioma. Too much surgery? Ann Hepatobiliary Pancreat Surg. submitted.

28 Liu Y, Wei X, Wang K, Shan Q, Dai H, Xie H, et al. Enucleation versus Anatomic Resection for Giant Hepatic Hemangioma: A MetaAnalysis. Gastrointest Tumors. 2017 Mar; 3(3-4):153-62. 
29 Cheng WL, Qi YQ, Wang B, Tian L, Huang W, Chen Y. Enucleation versus hepatectomy for giant hepatic haemangiomas: a meta-analysis. Ann R Coll Surg Engl. 2017 Mar;99(3): 237-41.

30 Sundar Alagusundaramoorthy S, Vilchez V, Zanni A, Sourianarayanane A, Maynard E, Shah M, et al. Role of transplantation in the treatment of benign solid tumors of the liver: a review of the United Network of Organ Sharing data set. JAMA Surg. 2015 Apr; 150(4):337-42.

31 Fu XH, Lai EC, Yao XP, Chu KJ, Cheng SQ, Shen F, et al. Enucleation of liver hemangiomas: is there a difference in surgical outcomes for centrally or peripherally located lesions? Am J Surg. 2009 Aug;198(2):184-7.

32 Prodromidou A, Machairas N, Garoufalia Z, Kostakis ID, Tsaparas P, Paspala A, et al. Liver Transplantation for Giant Hepatic Hemangioma: A Systematic Review. Transplant Proc. 2019 Mar;51(2):440-2.

33 Zhang W, Huang ZY, Ke CS, Wu C, Zhang ZW, Zhang BX, et al. Surgical Treatment of Giant Liver Hemangioma Larger Than $10 \mathrm{~cm}$ : A Single Center's Experience With $86 \mathrm{~Pa}$ tients. Medicine (Baltimore). 2015 Aug; 94(34):e1420

34 Liu Q, Liu F, Ding J, Wei Y, Li B. Surgical outcomes and quality of life between laparoscopic and open approach for hepatic hemangioma: A propensity score matching analysis. Medicine(Baltimore). 2019 Feb;98(6):e14485.

35 Lange UG, Bucher JN, Schoenberg MB, Benzing C, Schmelzle M, Gradistanac T, et al. Orthotopic liver transplantation for giant liver haemangioma: a case report. World J Transplant. 2015 Dec;5(4):354-9.

36 Bailey J, Di Carlo S, Blackwell J, Gomez D. Same day arterial embolisation followed by hepatic resection for treatment of giant haemangioma. BMJ Case Rep. 2016 Feb;2016: 2016.

37 Zhou JX, Huang JW, Wu H, Zeng Y. Successful liver resection in a giant hemangioma with intestinal obstruction after embolization. World J Gastroenterol. 2013 May;19(19): 2974-8.

38 Igarashi G, Mikami K, Sawada N, Endo T, Sueyoshi N, Sato K, et al. Interventional Treatment for Giant Hepatic Hemangioma Accompanied by Arterio-portal Shunt with Ascites. Intern Med. 2018 Oct;57(19):284751.

39 Akhlaghpoor S, Torkian P, Golzarian J. Transarterial Bleomycin-Lipiodol Embolization (B/LE) for Symptomatic Giant Hepatic Hemangioma. Cardiovasc Intervent Radiol. 2018 Nov;41(11):1674-82.

40 Gao J, Fan RF, Yang JY, Cui Y, Ji JS, Ma KS, et al. Radiofrequency ablation for hepatic hemangiomas: A consensus from a Chinese panel of experts. World J Gastroenterol. 2017 Oct; 23(39):7077-86.

41 Gao J, Ji JS, Ding XM, Ke S, Xin ZH, Ning CM, et al. Laparoscopic Radiofrequency Ablation for Large Subcapsular Hepatic Hemangiomas: Technical and Clinical Outcomes. PLoS One. 2016 Feb;11(2):e0149755.
42 Zhang X, Yan L, Li B, Wen T, Wang W, Xu M, et al. Comparison of laparoscopic radiofrequency ablation versus open resection in the treatment of symptomatic-enlarging hepatic hemangiomas: a prospective study. Surg Endosc. 2016 Feb;30(2):756-63.

43 Nguyen BN, Fléjou JF, Terris B, Belghiti J, Degott C. Focal nodular hyperplasia of the liver: a comprehensive pathologic study of 305 lesions and recognition of new histologic forms. Am J Surg Pathol. 1999 Dec;23(12):1441-54.

44 Giannitrapani L, Soresi M, La Spada E, Cervello M, D’Alessandro N, Montalto G. Sex hormones and risk of liver tumor. Ann N Y Acad Sci. 2006 Nov;1089(1):228-36.

45 Chandrasegaram MD, Shah A, Chen JW, Ruszkiewicz A, Astill DS, England G, et al. Oestrogen hormone receptors in focal nodular hyperplasia. HPB (Oxford). 2015 Jun; 17(6):502-7.

46 Laurent C, Trillaud H, Lepreux S, Balabaud C, Bioulac-Sage P. Association of adenoma and focal nodular hyperplasia: experience of a single French academic center. Comp Hepatol. 2003 Apr;2(1):6.

47 Wanless IR; International Working Party. Terminology of nodular hepatocellular lesions. Hepatology. 1995 Sep;22(3):983-93.

48 Gincul R, Lesca G, Gelas-Dore B, Rollin N, Barthelet M, Dupuis-Girod S, et al. Evaluation of previously nonscreened hereditary hemorrhagic telangiectasia patients shows frequent liver involvement and early cardiac consequences. Hepatology. 2008 Nov;48(5): 1570-6.

49 Cazals-Hatem D, Vilgrain V, Genin P, Denninger MH, Durand F, Belghiti J, et al. Arterial and portal circulation and parenchymal changes in Budd-Chiari syndrome: a study in 17 explanted livers. Hepatology. 2003 Mar; 37(3):510-9.

50 Kim T, Murakami T, Sugihara E, Hori M, Wakasa K, Nakamura H. Hepatic nodular lesions associated with abnormal development of the portal vein. AJR Am J Roentgenol. 2004 Nov;183(5):1333-8.

51 Bureau C, Péron JM, Sirach E, Selves J, Otal P, Vinel JP. Liver nodules resembling focal nodular hyperplasia after portal vein thrombosis. J Hepatol. 2004 Sep;41(3):499-500.

52 De Carlis L, Pirotta V, Rondinara GF, Sansalone CV, Colella G, Maione G, et al. Hepatic adenoma and focal nodular hyperplasia: diagnosis and criteria for treatment. Liver Transpl Surg. 1997 Mar;3(2):160-5.

53 Luciani A, Kobeiter H, Maison P, Cherqui D, Zafrani ES, Dhumeaux D, et al. Focal nodular hyperplasia of the liver in men: is presentation the same in men and women? Gut. 2002 Jun; 50(6):877-80.

54 Cherqui D, Rahmouni A, Charlotte F, Boulahdour H, Métreau JM, Meignan M, et al. Management of focal nodular hyperplasia and hepatocellular adenoma in young women: a series of 41 patients with clinical, radiological, and pathological correlations. Hepatology. 1995 Dec;22(6):1674-81.

55 Rubin RA, Mitchell DG. Evaluation of the solid hepatic mass. Med Clin North Am. 1996 Sep;80(5):907-28.
56 Weimann A, Ringe B, Klempnauer J, Lamesch P, Gratz KF, Prokop M, et al. Benign liver tumors: differential diagnosis and indications for surgery. World J Surg. 1997 Nov-Dec; 21(9):983-90.

57 de Rave S, Hussain SM. A liver tumour as an incidental finding: differential diagnosis and treatment. Scand J Gastroenterol Suppl. 2002; 37(236):81-6

58 Vogl TJ, Own A, Hammerstingl R, Reichel P, Balzer JO. Transarterial embolization as a therapeutic option for focal nodular hyperplasia in four patients. Eur Radiol. 2006 Mar; 16(3):670-5.

59 Birn J, Williams TR, Croteau D, Schwartz S, Sturza S, Getzen T. Transarterial embolization of symptomatic focal nodular hyperplasia. J Vasc Interv Radiol. 2013 Nov;24(11): 1647-55.

60 Virgilio E, Cavallini M. Managing Focal Nodular Hyperplasia of the Liver: Surgery or Minimally-invasive Approaches? A Review of the Preferable Treatment Options. Anticancer Res. 2018 Jan;38(1):33-6.

61 Hussain SM, van den Bos IC, Dwarkasing RS, Kuiper JW, den Hollander J. Hepatocellular adenoma: findings at state-of-the-art magnetic resonance imaging, ultrasound, computed tomography and pathologic analysis. Eur Radiol. 2006 Sep;16(9):1873-86.

62 Rooks JB, Ory HW, Ishak KG, Strauss LT, Greenspan JR, Hill AP, et al. Epidemiology of hepatocellular adenoma. The role of oral contraceptive use. JAMA. 1979 Aug;242(7): 644-8.

63 Baum JK, Bookstein JJ, Holtz F, Klein EW. Possible association between benign hepatomas and oral contraceptives. Lancet. 1973 Oct;2(7835):926-9.

64 Gong L, Su Q, Zhang W, Li AN, Zhu SJ, Feng YM. Liver cell adenoma: a case report with clonal analysis and literature review. World J Gastroenterol. 2006 Apr;12(13):2125-9.

65 Edmondson HA, Steiner PE. Primary carcinoma of the liver: a study of 100 cases among 48,900 necropsies. Cancer. 1954 May;7(3): 462-503.

66 Steinbrecher UP, Lisbona R, Huang SN, Mishkin S. Complete regression of hepatocellular adenoma after withdrawal of oral contraceptives. Dig Dis Sci. 1981 Nov;26(11): 1045-50.

67 Martin NM, Abu Dayyeh BK, Chung RT. Anabolic steroid abuse causing recurrent hepatic adenomas and hemorrhage. World J Gastroenterol. 2008 Jul;14(28):4573-5.

68 Bunchorntavakul C, Bahirwani R, Drazek D, Soulen MC, Siegelman ES, Furth EE, et al. Clinical features and natural history of hepatocellular adenomas: the impact of obesity. Aliment Pharmacol Ther. 2011 Sep;34(6): 664-74.

69 Labrune P, Trioche P, Duvaltier I, Chevalier $\mathrm{P}$, Odièvre $\mathrm{M}$. Hepatocellular adenomas in glycogen storage disease type I and III: a series of 43 patients and review of the literature. J Pediatr Gastroenterol Nutr. 1997 Mar;24(3): 276-9. 
70 Bioulac-Sage P, Rebouissou S, Thomas C, Blanc JF, Saric J, Sa Cunha A, et al. Hepatocellular adenoma subtype classification using molecular markers and immunohistochemistry. Hepatology. 2007 Sep;46(3):740-8.

71 Nault JC, Paradis V, Cherqui D, Vilgrain V, Zucman-Rossi J. Molecular classification of hepatocellular adenoma in clinical practice. J Hepatol. 2017 Nov;67(5):1074-83.

72 Dokmak S, Paradis V, Vilgrain V, Sauvanet A, Farges $\mathrm{O}$, Valla D, et al. A single-center surgical experience of 122 patients with single and multiple hepatocellular adenomas. Gastroenterology. 2009 Nov;137(5):1698-705.

73 van Aalten SM, de Man RA, IJzermans JN Terkivatan T. Systematic review of haemorrhage and rupture of hepatocellular adenomas. Br J Surg. 2012 Jul;99(7):911-6.
74 Pilati C, Letouzé E, Nault JC, Imbeaud S, Boulai A, Calderaro J, et al. Genomic profiling of hepatocellular adenomas reveals recurrent FRK-activating mutations and the mechanisms of malignant transformation. Cancer Cell. 2014 Apr;25(4):428-41

75 Zheng J, Sadot E, Vigidal JA, Klimstra DS, Balachandran VP, Kingham TP, et al. Characterization of hepatocellular adenoma and carcinoma using microRNA profiling and targeted gene sequencing. PLoS One. 2018 Jul 27;13(7):e0200776.

76 Ribeiro A, Burgart LJ, Nagorney DM, Gores GJ. Management of liver adenomatosis: results with a conservative surgical approach. Liver Transpl Surg. 1998 Sep;4(5):388-98.

77 Bieze M, van den Esschert JW, Nio CY, Verheij J, Reitsma JB, Terpstra V, et al. Diagnostic accuracy of MRI in differentiating hepatocellular adenoma from focal nodular hyperplasia: prospective study of the additional value of gadoxetate disodium. AJR Am J Roentgenol. 2012 Jul;199(1):26-34.
78 van Rosmalen BV, de Graeff JJ, van der Poel MJ, de Man IE, Besselink M, Abu Hilal M, et al.; Dutch Benign Liver Tumour Group. Impact of open and minimally invasive resection of symptomatic solid benign liver tumours on symptoms and quality of life: a systematic review. HPB (Oxford). 2019 Sep;21(9):1119-30.

79 Agrawal S, Agarwal S, Arnason T, Saini S, Belghiti J. Management of hepatocellular adenoma: recent advances. Clin Gastroenterol Hepatol. 2015 Jul;13(7):1221-30.

80 van Rosmalen BV, Coelen RJ, Bieze M, van Delden OM, Verheij J, Dejong CH, et al. Systematic review of transarterial embolization for hepatocellular adenomas. Br J Surg. 2017 Jun;104(7):823-35.

81 Chiche L, David A, Adam R, Oliverius MM Klempnauer J, Vibert E, et al. Liver transplantation for adenomatosis: European experience. Liver Transpl. 2016 Apr;22(4):516-26. 